\title{
A Framework for Teaching Mobile and Wireless Technology
}

\author{
Ric Jentzsch and Masoud Mohammadian \\ University of Canberra, Canberra, ACT, Australia
}

\author{
Ric.Jentzsch@canberra.edu.au \\ Masoud.Mohammadian@canberra.edu.au
}

\begin{abstract}
This paper discusses a framework for teaching of mobile and wireless technology. The framework is evolving with the numerous changes that are occurring in the related technology as well as the changes that are occurring in the teaching environment. In today's business environment the use of wireless applications is beginning to play an ever increasing important role. Many people use and interact with wireless and mobile devices each day both in their business and in their personal lives. Tomorrow's mobile business environment will be a force that can influence the competitive nature of business. The teaching of and about the technology and environment is only just beginning.
\end{abstract}

Keywords: wireless computing, teaching framework, wireless technology

\section{Introduction}

Teaching the use of technology or the technology itself comes with a certain amount of inherent risks and drawbacks. Most technology is upgraded every 18 to 24 months. During any year the technology may have, patches, service packs, add-ons, etc... New technology standards and related standards that affect the use of technology are being implemented and approved each year. In some technology areas new vendors are entering the market while some are leaving the market, and others are being amalgamated. Each of these modifications, changes, and standards, can slightly too dynamically affect the technology. These modifications and changes effect the way the technology works, can be used, is used, and its role as a business tool. The modifications potentially affect the way interactions between the human and the technology are dealt with, interactions between existing technologies, those begin used and considering to be used, and the user of the technology. In a teaching environment this means that the semester changes to the subject material might require some minor adjustments to the possibility that a massive overhaul of the teaching material is required. One technology area that is dynamically changing is mobile and wireless technology. The teaching of wireless and mobile technology brings about some inherent challenges and risks.

Material published as part of this journal, either on-line or in print, is copyrighted by Informing Science. Permission to make digital or paper copy of part or all of these works for personal or classroom use is granted without fee provided that the copies are not made or distributed for profit or commercial advantage AND that copies 1) bear this notice in full and 2) give the full citation on the first page. It is permissible to abstract these works so long as credit is given. To copy in all other cases or to republish or to post on a server or to redistribute to lists requires specific permission from the publisher at Publisher@InformingScience.org
This paper presents a framework for the teaching of mobile and wireless technology. The framework is based on the development of a subject where the teaching of the technology and feedback from a workshop presented at the International Conference on Intelligent Agents, Web Technology and Internet Commerce in Vienna, 
Austria February 2003. The framework is at a high level that will need to be reviewed for revisions on a periodic basis.

The framework takes the perspective of the stakeholders in today's organizations that will have to and do deal with this technology on a day to day basis. These stakeholders require not only an understanding of the terminology, but how it is being used by modern organizations, and the potential to which mobile and wireless technology might be applied in an organizational and business context.

\section{Teaching Environment}

The teaching of mobile and wireless technology requires an environment that few universities have or are willing to commit to. This is understandable with the number of ongoing changes that continues to drive the mobile and wireless industry and the expense that is required in order to be technologically up to date in this area. However, it is not understandable from the market potential for the future skills and knowledge needed by many employees. Many universities have implemented wireless systems on their campuses providing an extensible service to the educational activities offered to students (Monash, 2002; UniWide, 2003; UTORcwn, 2003). These implementations are directed at teaching supporting not at the teaching of mobile and wireless technology.

The objective of the development of a teaching framework for mobile and wireless technology is to first teach from an organizational perspective, particularly business organizations, and then from a technological perspective. The teaching needs to include the concepts and issues relating to the understanding of the use of mobile and wireless technology. The framework needs to consider how to react, within a reasonable timeframe, to the upgrades, patches, service packs, add-ons, standards, and business issues as they are discovered. The framework needs to provide a way to identify when each of these occurs and to be able to evaluate the potential affect that each could possible have on the business operations. A flow on affect is the ability to provide up to date information that would be integrated into the teaching material and the delivery method. For example an organization has recently installed a Wi-Fi local area network (WLAN) based on the 802.11b IEEE standard. The network has been designed to be used by the staff in the organization. Within six months of the operation of this WLAN a new Wi-Fi IEEE standard, $802.11 \mathrm{~g}$ is introduced. This new standard offers greater throughput and a higher level of security. The question is how should the organization react and on what basis should they react? This question is not new to the technology world, but it does take on a slightly different perspective in the mobile and wireless world. Within the framework, not only should the technology be defined but the questions, such as those posed above, need to be addressed.

The development and application of the framework addresses how the technology can be demonstrated or a reasonable set of uses demonstrated. Some of these demonstrations can be based on a relatively simple business environment case. For example: a hotel sends an SMS message to his/her mobile device confirming a booking. This might look like:

Reservation confirmation: 10 Oct $03-12$ Oct 03

Name: J. W. Swartz

Confirmation: Q256SWARTZ

Another example might be where a meeting has been scheduled and for some reason the location has had to be changed due to unforseen circumstances. A demonstration of this type could be more complicated including a time change and where several parties who are in diverse locations need to be informed. These changes would not only have to be communicated to all relevant 
parties, but potentially all the parties would need to know things about the new location, such as parking facilities at that location, and possibly provide directions to the location site as well as a room within that site. Whereas the SMS message is relatively small, this situation requires more information and possibly the need to a response from the receiver(s) of the message.

\section{Framework}

One thing that can be counted on in the wireless and mobile technology environment is change. One reason for this is the on-going changes through out the telecommunications industry. These changes have been and are being driven by technological advances. These advances include such things as the capabilities of the hardware, the proliferation of the wireless infrastructure and the move to such initiatives as the $3 \mathrm{G}$ (and beyond) wireless network. These changes affect mobile and wireless applications that affect how and where individuals and organizations use them. Figure 1 presents the components of the framework. The framework includes: facilities, tools, and infrastructure. In the middle that ties the three together is application. Application is a support function necessary to manage, integrate, and control the outlying three components.

No component in this framework is meant to be independent of any other. The weighting of a particular component may vary depending on internal and external influences. All three components are dependent on each other to various degrees and in various ways.

Let us look at each of these components in

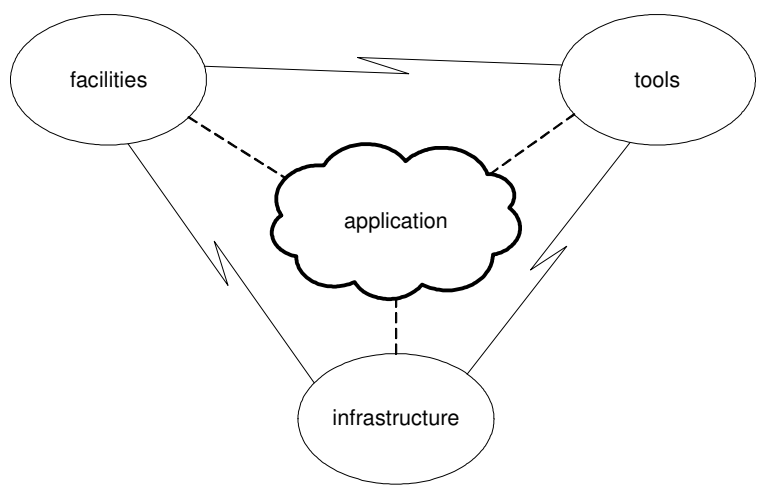

Figure 1: Teaching framework more detail.

\section{Application}

Application is applying and integrating the three components for the facilitation of the framework in a teaching environment. This facilitation provides a basis for information dissemination and knowledge acquisition. In providing a well structured environment, the application considers integration, audience, environment, and administration.

Integration brings together the three outlying components from a technological perspective. Integration is an important element in achieving the outcomes from the subject matter.

The audience perspective is used to emphasis and directs the perspective of the subject material. Audience addresses student background and course of study. Included in this understanding of the audience includes such things as the students':

- $\quad$ general business knowledge;

- level of information technology knowledge based on work experience; and

- information technology education over the past three years. 
The intended audience influences the depth of needed knowledge of tools, types of tools, and infrastructure. Identifying the parameters of the particular audience provides a basis for determining the weighting of a particular framework component. For example if the audience is predominately business students doing an Master of Business Administration (MBA) course of study, the depth of understanding of the infrastructure would need to be greater than the depth of understanding of the tools. For Masters of Information Technology (MIT) students the depth of understanding and use of the tools needs to be greater than the business side. It is a matter of where the emphasis is placed while keeping the teaching material cross functionally integrated and balanced with all other components. The selection an editing/authoring tool will influence the infrastructure. The infrastructure and tools influence the facilities and the converse is also true.

Administration is a support function. This includes such things as technical support and unit information dissemination to ensure a smooth operation of the tools within the infrastructure though the facilities. Administration support requires technical support that is needed to ensure that wireless access is setup for all participants and that the appropriate security settings are monitored and maintained.

The environment refers to the three wireless perspectives. These perspectives are shown in Figure 2.

\section{Environment}

Each environment has a different business application perspective. Coyle (2001), Elliott and Nigel (2004), and Vos and DeKlein (2002) discuss these wireless environments from particular perspectives and with differing emphasis. These wireless environments are classified by their effective range, location environment, and use. Wireless Personal Area Networks (WPAN or just PAN) has a short distance range, in and about the 10 metre or less range. Short range devices are intended

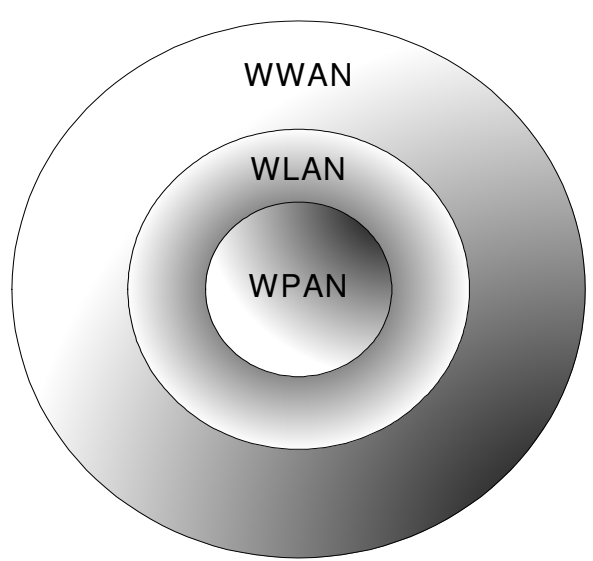

Figure 2: Wireless Environments to be used in connecting such things as peripheral devices and personal communication devices. PAN tend to be localized around the particular user. Wireless Local Area Networks (WLAN) is in the 100 metre or less range. The intended use of a WLAN includes such devices as portable computers as well as personal communication devices. WLAN tend to be localized around the user's particular environment. Wireless Wide Area Networks (WWAN) are part of the cell phone system, thus have a range of about 30 kilometres. Here the devices tend to be mobile personal communication devices as the user changes location over a long distance. WWAN tends to be global around the particular user's location.

There are various facts that affect these ranges, thus the ranges here are given in general terms. The devices and uses are but examples as there are many others that are coming to market nearly every week.

\section{Wireless Personal Area Networks (WPAN / PAN)}

PANs can be dynamic or static. Each has its uses in business. There are comparatively few technologies in each category but many potential uses. Some of these technologies have been around for five to six years, while others have only been around for one or two years. Because of the relative newness, getting resources that can be used for teaching in this area is not easy. 
For some of the technologies it is relatively easy to find books and journal articles that discuss the technology as well as how it is being used. With new technologies to be competitive, the vendors of the technology need to be actively reacting to competition and what users (individuals and business) want. What this tends to do is provide an environment that evolves at an accelerated rate. First from what the users think they need to what they actually get and second from what the vendors of the technology can provide and do provide. And third both hardware and software developers are often unable to keep up with the changing specifications that might be hardware dependent. These three things make teaching of this material very difficult.

A more problematic area, in this environment, is trying to demonstrate the use of the various technologies in a business environment. The best that has been achieved thus far is to utilize case studies of what is and has been done and then extrapolate out future considerations for business. The teaching needs to include what technologies are available, why they are beings used for, how they are being used, and under what conditions are these technologies being used.

\section{Wireless Local Area Networks (WLAN)}

If the teaching organization has a WLAN in place and it is readily accessible, then it is a matter of being able to utilize that existing infrastructure. WLAN can be though of as an extension of the wired LAN. Thereby applications become device dependent particularly at the wireless mobile device end. For example, we might explore what applications can be and have been developed to run on a PDA that interacts in the trading of information via the WLAN. This might include push and pull information either of a generic nature, such as news, weather, and sports or it might be keeping a person informed of their schedule.

Demonstration of the business concepts, applications, and issues is a matter of utilizing case studies and existing applications. A set up of a wireless network between portable computers can be done and used to illustrate many of the concepts and issues. Wireless network cards for portable computers are relatively inexpensive. However, in trying three different brands of PC wireless network cards late in 2003 , the use and results were quite different.

\section{Wireless Wide Area Networks (WWAN)}

With the introduction and growth in the use of cell phones, business and individuals are finding new ways to communicate. Most users today are familiar with the basic functions of cell phones. However, it has only been in the last three years that some of the features offered by these devices have begun to filter into the business environment. One of those features is the use of short message system (SMS). An example of the use is given on page 2. In teaching this technology the use of the tools is an important element. For illustrating SMS messaging, there are ways of using the wired network to send SMS messages to cell phones.

As changes in the cell phone telecommunication industry occur, with the introduction of the $3 \mathrm{G}$ wireless phone network (that will replace the current $2 \mathrm{G}$ network) there are even increasing ways that business can use these devices. One of the major differences between the existing cell phone network and the $3 \mathrm{G}$ network is the speed of data transfer. As the $3 \mathrm{G}$ network becomes more integrated into society then the teaching of ways of using it for business will also expand. At this point it is difficult to illustrate these changes. There are several reasons for this. First there are few devices that are $3 \mathrm{G}$ enabled available at a reasonable cost. The overall access to a $3 \mathrm{G}$ network is only in its infancy and mostly based in few large metropolitan areas. There are other $3 \mathrm{G}$ considerations that with time like most technology will be solved, resolved, or over come in one way or another. 


\section{Standards}

In teaching about the wireless environment types, one must include the standards that each works with and the standards body that is affecting what is happening in that area. In the PAN and WLAN environments the major standards bodies are IEEE and ETSI. IEEE deals with the 802.1x standards where as the ETSI deals with HiperLAN. There are standards that deal with HOMERF / SWAP that have been targeted towards home electronics.

Standards flow into the WWAN area as well. This is an area that illustrates some diversity. In this arena you have various standards in the technologies. Theses technologies can use WAP (Vos and DeKlein 2002). Standards and WWAN issues relate to such acronyms as: GSM, GPRS, UMTS, CDMA, CDMAOne, CDMA2000X, TDMA, AMPS, EDGE, and PDC (Vos \& De Klein 2002). Some of these are based on wireless telephone $2 \mathrm{G}$ standards others are based on the more current $3 \mathrm{G}$ standards. In this area, much is dependent on which part of the world you are talking about. The global issues need to be considered as students nowadays come from different parts of the world.

The teaching framework provides a platform for the discussion of the development of these various standards, where they are being used, and their respective advantages and drawbacks.

\section{Facilities}

The facilities include the standard things that any teaching environment should have. The facilities should include: a well organized class room, a white or black board for illustrating and outlining, an overhead project connected to a wired or wireless computer, and a computer that has access to both the Internet and internal local area network. Available materials to support current events and information resources need to be readily accessible via a class Web site. Students will need to have access to laboratories where the appropriate tools can be worked with and accessed from the classroom.

Since the subject deals with wireless and mobile technology, the teaching facilities should include some additional add-on facilities. First in order to demo any application or concept, it is best if this can reflect the environment that the students will have as well as simulate real world applications. Ideally this means that a portable computer as well as a PDA, or similar device, with at least a wireless network interface card is available, readily accessible, and configured with the appropriate access requirements. The facilities need to be able to reflect the positive aspects as well as the drawbacks of mobile devices. These include such things as screen size, shape, colours, connectivity, and environment interference. Ideally these drawbacks as well as the positive aspects can be reflected via an overhead projector facility simulating the wireless device. This can be very expensive and complex to create and manage. Care needs to be taken so that adverse affects are not derived from conflicting devices or their connectivity.

\section{Tools}

Tools are software support that includes the development environment such as editing/authoring tools, smart editors, debugging tools, conversion tools, emulation tools, model development and displays. Tools are used to illustrate, develop, and demonstrate concepts, issues, and features. Selecting a tool is not a quick or an easy task. The framework does not specify a specific tool as it is not about learning a specific tool, but about the use of a tool to illustrate and demonstrate what and how businesses can operate in a wireless environment.

Let us divide the tools into categories. First the general list and then the software development kits (SDKs). The reason for this is the functionality of the two, the amount of space (both in 
storage and memory) that is required, learning curve of the tool, and the environment the tool is predominantly directed towards.

\section{Editing / Authoring Tool}

To begin with, WAP is a wireless application protocol much like wired Web protocols. To create an Internet Web page that uses http (hypertext protocol) you would use something like html (hypertext markup language). To create a wireless application for WAP you would use a wireless mark-up language (WML) or wireless script language. WML is a reduced sub-set of XML. The reduction of XML to WML is necessary to accommodate the slower wireless data transfer rates as well as wireless device's limitations. (Taylor \& Heltick, 2002; Zindell, 2003)

Other development environments for WAP applications would include xHTML and vendor specific products such as those from Nokia, Ericsson, Motorola, and OpenWave. These vendor products are often referred to as software development kits (SDK) and are targeted at the vendor's particular products or products with the same specifications.

Tools will vary by the environment that they are used to support. For example, different tools are used for cell phones and for PDAs, than are used with personal area network devices.

\section{Authoring tools}

Let us begin by looking at the users that some of the WAP and WML authoring tools are directed at. By no means is this intended to be an exhaustive list as new tools, upgrades, and patches are forth coming every month, while some are dropped and not supported. The targeted user level has been developed first by downloading and trying to install and use the editor. Then the capability of each was looked at in respect to the assumed knowledge of a user. Finally the tool was evaluated to see at what level the tool could be used to actually create a WAP application. For additional details see Webattack (2003), WML editors (2003), or the Palowireless Resource Center (2003). (See Table 1.)

Table 1: WAP and WML editors

\begin{tabular}{|c|c|c|c|c|}
\hline \multirow{2}{*}{ Tool Name } & \multirow[b]{2}{*}{ Editor } & \multicolumn{3}{|c|}{ Suggested User Level } \\
\hline & & Novice & Intermediate & Experienced \\
\hline 3tlWBuilderexpresso & WML & $\mathrm{X}$ & $\mathrm{X}$ & - \\
\hline DotWAP & WAP & $X$ & - & - \\
\hline NetObject & WML extensions & - & $\mathrm{X}$ & $\mathrm{X}$ \\
\hline TextPad & WML & - & $\mathrm{X}$ & - \\
\hline WAPPage & WML & - & $\mathrm{X}$ & - \\
\hline WAPTop & WML & - & $\mathrm{X}$ & - \\
\hline WaveDev.com & WML & $\mathrm{X}$ & - & - \\
\hline CoffeeCup & WAP & $X$ & - & - \\
\hline Cardone & WML & $\mathrm{X}$ & - & - \\
\hline
\end{tabular}


Table 2: Wireless Emulators and Micro-browsers

\begin{tabular}{|l|l|}
\hline Organization & Comments \\
\hline Ericsson & $\begin{array}{l}\text { R380 emulator WML applications for the WAP browsers for Ericsson } \\
\text { enabled devices }\end{array}$ \\
\hline Opera & Version 4Supports xml, wml, and wbmp \\
\hline M3Gate & $\begin{array}{l}\text { View WAP pages on desktop, WML and WML script supported, an add-on } \\
\text { to major browsers }\end{array}$ \\
\hline Yospace & Smartphone emulator, with Java applet via Web site support \\
\hline Au-System & Support multiple wireless device interfaces \\
\hline Wapsody & Simulates WAP and provides a WAP application builder \\
\hline Wapman & Portable browsing device \\
\hline WINWAP & WML browser can be used to browse local or Internet WML applications \\
\hline Pagea Waplet & Java applet-based WAP emulator and WML browser \\
\hline Palm & Emulates Palm devices needs the skin for each device \\
\hline
\end{tabular}

Overall this evaluation is relatively subjective, as the full testing of each has not been done and in many case can not be done without spending a great deal of resources.

Not all are free, some are shareware and some are freeware. Some are designed to work with a particular operating system, while others can only be used with selected operating systems. For example DotWAP runs on Win32 platforms and is freeware (Inetis, 2001). Some provide support for several languages.

When looking for an editor or authoring or development tool, there are various terms used. Some use WAP, while others use WML or WML Script (a more advanced version of the plain vanilla WML). There are various Web sites that provide a good list as well as download capabilities to many authoring tools (Palowireless, 2003; Webattack 2003; WML Editors, 2003).

A WAP application developer can create complete applications without the need for a handset or even access to carrier infrastructure. Developers can test and demonstrate WAP applications by navigating and requesting URLs on any WAP gateway or on any Web server on the Internet. For additional material see 2thumbs WAP.com (2001).

\section{Emulation and emulators}

Mobile devices such as the cell phone, PDA, Palm, tablet PC, and other portable devices have different interface requirements than those of the wired devices such as desktop computers (Coyle, 2001; Elliott, 2004). The ability to emulate those interfaces requires the use of some type of emulator. If the content that is intended to be displayed on the wireless device is Web based, then some type of micro-browser should be employed. A micro-browser gives the device the ability to access the Internet and obtain wireless formatted information. Remembering that these devices currently have limitations in such areas as screen size, screen display, amount memory, and access speeds. (See Table 2.)

A good emulator can serve dual purposes. It can be used on a PC to browse WML applications on the Internet and as well as to test local WML applications on wireless device screens. The 
purpose of the emulator is to provide an opportunity to test the look and feel of WAP and WML applications on selected devices.

The term skin is often used to define a set of screens for a particular device (PalmSource, 2003; Symbian, 2003). Vendor specific devices require the downloading of skins that are generally bit map, to emulate their various devices. Some, such as Ericsson, are vendor product specific while others such as Opera are vendor device independent (Naraine, 2002). Many have a small footprint thus require a small amount of storage. However, like all software, the more that is included in the package, the more disk storage and memory is required.

\section{Software Development Kits}

Software Development Kits (SDK) are complete development environments. These tool kits offer developers an environment for creating, testing, and demonstrating wireless applications. Many of the SDKs include tools for creating WML and WML Script content, Web bit map (WBMP) graphics, debugging the wireless applications and simulating the WAP content on enabled wireless devices. Some of these kits convert GIF and JPEG to WBMP. A full feature SDK includes sample codes, templates for the vendor devices, xHTML support, server simulator based on WAP server or WAP gateways, and MMS support. With so many things offered in a SDK the learning curve is very steep. In trailing one SDK, it was estimated that to become efficient at using it in its full development environment would require at least six months. (See Table 3.)

Table 3: Wireless Software Development Kits (SDK)

\begin{tabular}{|l|c|l|}
\hline \multicolumn{1}{|c|}{ Organization } & Storage Required & \multicolumn{1}{c|}{ Source } \\
\hline Nokia & $17.2 \mathrm{MB}$ & $\underline{\mathrm{http}: / / \mathrm{www} . f o r u m . n o k i a . c o m / m a i n / 1,6566,030,00 . \mathrm{html}}$ \\
\hline OpenWave & $53 \mathrm{MB}$ & $\underline{\mathrm{http}: / / \text { developer.openwave.com/ }}$ \\
\hline Ericsson & $7.65 \mathrm{MB}$ & $\begin{array}{l}\underline{\mathrm{http}: / / w w w . e r i c s s o n . c o m / m o b i l i t y w o r l d / s u b / n e w s / S u b P a g e ~} \\
\text { s/mps_sdk_6_beta }\end{array}$ \\
\hline Motorola & $\begin{array}{c}\text { Varies with optional } \\
\text { components }\end{array}$ & $\begin{array}{l}\text { http://www.motocoder.com/motorola/pcsHome.jsp?rNum= } \\
647507091 \& \text { node_name=Tools_SDKs }\end{array}$ \\
\hline
\end{tabular}

\section{Conversion Tools}

There are tools that work with the wireless graphic (wbmp) files that can be used in WAP pages. Some support JPG, GIF, BMP and WBMP graphic file types. These tools include those that are or can be used to convert existing html Web pages into something that can be used in the mobile device. The WBMP Graphics editor enables you to create graphics in WBMP format or convert GIF and JPEG images to WBMP format.

As the telecommunication environment continues to change and more and more $3 \mathrm{G}$ networks and $3 \mathrm{G}$ enabled devices become available, there will be many new advantages. One of the main advantages of MMS over SMS, is the ability to include graphics in your content. The leap from text based HTML in its infancy, to the World Wide Web as we know it today, was long and tedious. The introduction of WBMP images in the WML standard is only the first step towards a more graphically stimulating wireless experience. 


\section{Infrastructure}

Infrastructure is what the organization needs technologically as well as organizationally to participate in the teaching of the wireless and mobile environment.

Infrastructure is tightly integrated with each environment. For the WLAN the major infrastructure areas that need to be consider are:

- Wireless access points; and

- Wireless interface cards of one type or another.

There are a variety of vendors for the various products and not all products work alike or can be used in the same way. Hereto the differing standards, such as IEEE, will influence what can be done and its speed of operation.

For PAN and WWAN the major infrastructure to be considered is centred on:

- Wireless devices - these can be static or dynamic.

Regardless of infrastructure the teaching needs to discuss not only the development of the wireless system but other such things as: security, location, and the effects of differing standards.

\section{Constraints}

Some of the immediate constraints that should be noted are in the tools themselves. Software development kits, targeted at WWAN, take a lot of storage space and have a very high learning curve. Some SDKs include various components that can be used on PAN application development, but these tend to be very complex and vendor product specific.

Shareware vs. freeware is a consideration. If you buy something, given the changes in the technologies that are occurring, consider how long it will take to achieve some return on the investment. If freeware is used, then any and all problems associated with the product are the users' problem. Freeware may require that you be a registered user. As a registered users you will receive lots of developer e-mail. Some of it is helpful and some is just advertising.

Editors and authoring tools are not all alike. The freeware ones may have three or even ten different interfaces that they can emulate. With the number of new mobile and wireless devices coming to the market each year, there is no guarantee that the particular editor will be able to keep up. Not only that, but developing a WML application for WAP and testing it on one device will rarely look the same on a different device. This is especially true in testing a cell phone as well as the various vendor models and types of PDAs. In some cases the same vendor model will be manufactured by different organizations. In one reported case, it has been illustrated that the same model manufactured under the same specifications does not have the exact same display. This is partly due to the materials used and some manufacturing specifications that are left open to the particular manufacturer.

Emulators can be tricky to use and do not always reflect what the device will show. But they are good indicators of what the user might see. Like with other tools you can buy or download for free with all the same constraints as noted above.

The educational facilities such as demonstration rooms and labs are an essential part of teaching. Few, if any, teaching institutions are willing to invest in the level of facilities that are needed to fully support or manage this type of education. The market for students in this area is still growing but educational facilities to accommodate that market is yet to realize that potential. Developers for wireless mobile applications currently tend to be more vendor specific and trained by the particular vendor. As standards are developed and the use of wireless business grows the 
need for those who understand the technology and those who have the skills to develop within the technology.

There is insufficient knowledge and lack of commitment by both university management and technical staff. This is an area that, like other technology areas in the past, will take time to build. However, as has been experienced over two years, many barriers exist within the university environment.

Students who are interested in mobile and wireless technology have found a need to know more through their university education. Yet when looking at the job guides, it appears that these jobs are more for engineers or for those who want to sell these products. The job prospects in this area are growing and will continue as more and more businesses identify ways exploit their competitive advantage using mobile and wireless business initiatives. The job ads for wireless security positions have tripled in two years.

\section{Future Directions}

The framework will continue to be put to its test and as the technologies change and the environment changes, changes in the framework will occur. These changes will endeavour to incorporate and reflect the changes to the mobile and wireless industry, tools, and products available. Research into how businesses can use PAN, WLAN, and WWAN in an integrated business environment requires a great deal of work. Some of the research that is currently underway is how to best integration innovative business applications with small to medium enterprises. What is the future and current direction in mobile commerce transactions (mobile ticketing, mobile auctions, tourism / leisure applications) and in mobile health systems (emergency messaging, ubiquitous health care, telecare, mobile phone data emergencies, mobile crises handling). In the health systems, the authors are completing a paper on the development and use of radio frequency identifiers for hospital patient administration. Some other areas that are currently being discussed are: user location awareness, environment awareness / situation analysis (noise, humidity), devices capable of accessing multiple networks at the same time, and non intrusiveness of content - user perspective.

Overall the framework has proven to be useable and viable, but as each successive change occurs changes may need to make the framework broader and more encompassing.

\section{References}

2thumbs WAP.com. (2001). Wireless downloads. Retrieved 30 October 2003 from http://www.2thumbswap.com/downloads/index3.htm

Coyle, Frank P. (2001). Wireless Web: A manager's guide. Addison-Wesley Publishing.

Elliott, G. \& Phillips, N. (2004). Mobile commerce and wireless computing systems. Person Education, Addison-Wesley Publishing

Inetis. (2001). Retrieved 28 October 2003 from http://www.inetis.com/freeware.asp

Monash University. (2002). Retrieved 28 September 2003 from http://www.its.monash.edu/networks/wireless/faq.html

Naraine, R. (2002, December 18). Opera 7 adds power-browsing in Beta 2. Internetnews.com. Retrieved 02 October 2003 from http://www.internetnews.com/xSP/print.php/1558891

PalmSource. (2003). Palm OS Emulator. Retrieved 11 October 2003 from http://www.palmos.com/dev/tech/tools/emulator 
Palowireless Resource Center. (2003). Retrieved 12 October 2003 from http://www.palowireless.com/wap/visualtools.asp

Symbian. (2003). OS technology. Retrieved 08 October 2003 from http://www.symbian.com/index.html

Taylor, S. \& Heltick, L. (2002). Network world convergence newsletter. Retrieved December 162002 from http://www.nwfusion.com/newsletters/converg/2002/01668168.html

UniWide. (2003). Frequently asked questions. UniWide: UNSW Campus Wide Wireless Network. Retrieved 28 September 2003 from http://www.uniwide.unsw.edu.au/faq.htm.

UTORcwn. (2003). Frequently asked questions. The University of Toronto. Retrieved 28 September 2003 from http://www.wireless.utoronto.ca/faq.php

Vos, I. \& De Klein, P. (2002). The essential guide to mobile business. Upper Saddler River New Jersey, USA: Prentice Hall.

Webattack.com. (2003). WAP Development. Retrieved 12 October 2003 from http://www.webattack.com/Shareware/webpublish/swwapdev.shtml.

WML Editors. (2003). A list of some of the WML editors. Retrieved 12 October 2003 from http://www.wap-shareware.com/directory/wmleditors.shtml

Zindell. (2003). Developing WML documents for wireless devices. Retrieved 21 October 2003 from http://www.zindell.com/course.jsp?code=soft502,

\section{Biographies}

Dr. Ric Jentzsch is a senior lecturer at the University of Canberra, Canberra, Australia. He holds a Ph.D. in Computer Science from University of New South Wales, Australia and a Masters in Computer Information Systems from Colorado State University, Fort Collins, Colorado, USA. He has taught in database, e-commerce, and business wireless computing for the past ten years. Ric's current research interests are in small to medium organizations electronic business frameworks, business integration of wireless technology, intelligent agents, electronic content management, and emerging technologies diffusion and integration for SMEs. Ric has worked for private and government agencies. He has over 59 publications in information technology and has been an invited speaker to many private organizations.

Dr. Masoud Mohammadian has completed his Bachelor, Master and $\mathrm{PhD}$ in Computer Science in Australia. He is currently a senior lecturer at the school of computing at the University of Canberra in Australia. He is a senior member of several professional (computing and engineering) organizations. He is was the chair of the Institute of Electrical and Electronic Engineering (IEEE) ACT section in 2001. His research interests lie in Intelligent and adaptive systems, Intelligent Agents, fuzzy logic, genetic algorithms, neural networks and their applications in information retrieval, data mining, industrial automation, financial and business problems which involve real time data processing, planning and decision making. He is a member of over 30 international conferences and he has chaired several international conferences in intelligent agents and computational intelligence. He was the chair of the 2001 and 2003 International Conference on Intelligent Agents, Web Technologies and Internet Commerce. He has chaired several international conferences in computational intelligence.He has a over seventy publications in Computational intelligence and intellignce agent system. He has also edited 11 books in computational intelligence and intelligent agents. 